\title{
Decadal changes in heat-related human mortality in the eastern United States
}

\author{
Robert E. Davis ${ }^{1, *}$, Paul C. Knappenberger ${ }^{2}$, Wendy M. Novicoff ${ }^{3}$, Patrick J. Michaels ${ }^{1}$ \\ ${ }^{1}$ University of Virginia, Department of Environmental Sciences, PO Box 400123, Charlottesville, Virginia 22904-4123, USA \\ ${ }^{2}$ New Hope Environmental Services, 5 Boar's Head Lane, Suite 101, Charlottesville, Virginia 22903, USA \\ ${ }^{3}$ University of Virginia, Department of Health Evaluation Sciences, School of Medicine, Box 800717, HSC, Charlottesville, \\ Virginia 22908, USA
}

\begin{abstract}
One hypothesized impact of climate warming is higher human mortality rates in the warm season, due to increasingly hot and/or humid conditions. On days with high afternoon apparent temperatures, we compared changes in daily mortality rates over 4 decades in 6 major metropolitan areas along a north-south transect in the eastern US. In the 3 southernmost cities examined, we found few significant weather-mortality relationships for any decade or demographic group. But in the 3 northern cities, we determined that statistically significant declines in population-adjusted mortality rates occurred between 1964 and 1994 for the total population and the white and elderly demographic subgroups during hot and humid weather. These statistically significant reductions in hot-weather mortality rates suggest that the populace in cities that were weather-sensitive in the 1960s and 1970s have become less impacted by extreme conditions over time because of improved medical care, increased access to air conditioning, and biophysical and infrastructural adaptations. This analysis counters the paradigm of increased heat-related mortality rates in the eastern US predicted to result from future climate warming.
\end{abstract}

KEY WORDS: Human mortality $\cdot$ Climate change $\cdot$ Heat stress $\cdot$ Apparent temperature $\cdot$ Eastern United States

Resale or republication not permitted without written consent of the publisher

\section{INTRODUCTION}

In northern US cities, human mortality rates are significantly elevated on hot and humid days (Oeschli \& Buechli 1970, Bridger et al. 1976, Kalkstein \& Davis 1989, Kalkstein \& Greene 1997, Davis et al. 1999, 2000) particularly among the elderly (Henschel et al. 1969, Oeschli \& Buechli 1970, Lye \& Kamal 1977, Applegate et al. 1981, Jones et al. 1982, Greenberg et al. 1983, Kunst et al. 1993, Kilbourne 1997). Although a fraction of these deaths can be directly attributed to the heat, the majority are ascribed to causes of death not obviously considered to be 'weather-related,' such as circulatory and respiratory diseases (Keatinge et al. 1986, Larson 1990a,b). Similar increases in total and elderly

*E-mail: red3u@virginia.edu mortality have also been associated with hot weather in Eurasia (Katsouyanni et al. 1993, Kunst et al. 1993).

Observed increases in summertime apparent temperatures across much of the US have led to speculation that mortality rates will rise (Gaffen \& Ross 1998). Localized warming associated with growing urban heat islands has raised ambient temperatures for most of the metropolitan population (Landsberg 1981). Given the historic linkage between high temperatures and death, future temperature projections from climate models have led scientists and public health officials to forecast significant increases in mortality to arise from human-induced greenhouse warming (Kalkstein \& Greene 1997, Gaffen \& Ross 1998, Chestnut et al. 1998). However, most, if not all, of these forecasts are based upon steady-state weather-mortality models that implicitly assume weather-mortality relationships are time-invariant. In contrast, we hypothesize here 
that US mortality associated with warm and humid days has systematically declined over time.

The goal of this project is to determine whether there have been temporal changes in the relationship between human mortality rates and apparent temperatures on hot, humid days. Using daily weather and mortality data, we examine mortality rates over 4 decades in 6 major metropolitan areas in the eastern US to determine whether mortality rates on hot, humid days have systematically changed on a decadal basis.

\section{DATA}

Because the weather in most of the eastern US is highly variable both temporally and spatially, proper analysis of weather-mortality linkages requires the use of daily mortality records at specific locations. Mortality data were obtained from the National Center for Health Statistics (NCHS 1994). These records include documentation on each death recorded in the US as compiled from death certificates and include the date, place, and cause of death and demographic factors such as the age, race, and sex of the decedent. We examined data from 1964-66 and 1973-94 for a total of 25 yr of daily mortality data. (Data from 1967-72 were not used for this study because the date of death was not systematically reported. This analysis ended with data from 1994 because subsequent years had not yet been archived in digital form by the NCHS at the time this analysis was performed.) We analyzed these data to evaluate decadal trends in total, elderly, white, and minority mortality on warm and humid days.

Our method requires data aggregation over large metropolitan areas with sufficient daily deaths to generate statistically robust mortality time series. Weathermortality relationships were evaluated in 6 cities along an approximate north-south transect in the eastern US (Boston, MA; New York City, NY; Philadelphia, PA; Charlotte, NC; Atlanta, GA; and Miami, FL).

We used the 1990 definitions of the counties that comprise each metropolitan statistical area (MSA) and US Census data to define the population of each city (US Dept of Commerce 1992). For example, Boston is comprised of Essex, Middlesex, Norfolk, Plymouth, and Suffolk Counties according to the 1990 MSA definition. Urbanization has resulted in the addition of counties to some official MSA definitions over time, so rural counties not designated within an MSA in the 1960s, for example, were nevertheless included in our analysis to maintain temporal sampling consistency.

Using energy-balance principles, biometeorologists have demonstrated that humans respond physiologically not only to temperature but to a combination of temperature and humidity, among other factors (Stead- man 1979, 1984). Biometeorologists have thus developed a variety of indices of atmospheric conditions in an effort to determine how humans react to environmental stressors (Kilbourne 1997). One such measure, called the 'apparent temperature' (AT) or 'heat index', combines air temperature and humidity into a single variable (Steadman 1979, 1984). This index of the relative 'sultriness' of the air serves as the basis for the heat advisories issued by the National Weather Service.

A wide variety of other comfort indices exist, many of which are based upon sound biophysiological principles (e.g., Ayoade 1978, Lee 1980, Kilbourne 1997, Höppe 1999, Matzarakis et al. 1999). Although some of these measures have been determined to be superior to AT in certain biometeorological applications, their widespread use has been hindered by the need for more extensive input data. In this research, while we recognize the potential advantages of some of these indices, we nevertheless employ AT because it is considered the US standard; however, we hope to explore the application of alternate comfort indices in future work.

\section{METHODS}

To account for population and demographic changes both within and between cities over time, daily mortality counts were standardized relative to a hypothetical standard city with a population of 1 million people. The demographics of that standard city are based on projections of the age distribution of the entire US populace in the year 2000. We age-adjusted our data using the direct standardization method (Anderson \& Rosenberg 1998). County-level population data were acquired from US Census sources for 1960, 1970, 1980, and 1990 for 10 age categories (US Dept of Commerce 1992), and the population of intervening non-census years was estimated via linear interpolation. Individual standardized death counts were aggregated into a total daily mortality category (age-adjusted daily mortality rate) as well as into white, non-white, and elderly ( $\geq 65 \mathrm{yr}$ ) cohorts for each MSA. To investigate changes in weather-mortality relationships over time, the daily totals in each mortality class were aggregated by decade. Because of the lack of data from the 1960s, we defined our 3 'decades' as the 1960s-70s (10 yr), the 1980s (10 yr) and the 1990s (5 yr) to provide more statistically robust decadal samples.

Hourly weather data were obtained for each city from the National Climatic Data Center (1993, 1997) and data were extracted at 16:00 h local standard time (LST), approximating the average time of daily maximum summer temperatures. In many instances, death occurs several days after the offensive weather event 
(Rogot \& Padgett 1976, Bull \& Morton 1978, Kalkstein \& Davis 1989, Gorjanc et al. 1999), which necessitates the examination of possible lagged relationships. We compared mortality rates with several weather variables, including morning and afternoon temperature, dew-point temperature, and AT for the 6 MSAs at lags of 0 to $3 \mathrm{ds}$. The strongest relationships were consistently uncovered with afternoon (16:00 h LST) AT and a $1 \mathrm{~d}$ lag, although the results were similar using $1 \mathrm{~d}$ lagged morning dew-point temperature, in agreement with prior research (Kalkstein \& Davis 1989, Smoyer et al. 2000). Afternoon AT, lagged by $1 \mathrm{~d}$, was chosen as the independent variable in this analysis.

The strength of relationships between daily weather conditions and mortality varies seasonally. In the US and other countries, mortality is higher in winter than in summer (Langford \& Bentham 1995, Donaldson \& Keatinge 1997, Eurowinter Group 1997, Lerchl 1998), possibly because of increased transmission rates of infectious diseases such as influenza (Monto \& Kioumehr 1975, Mandell et al. 1995). Though winter death rates are higher than those in summer, daily mortality is not typically highest on the coldest winter days. When examined on a daily (as opposed to a weekly, monthly, or seasonal) basis, mortality is more closely coupled to daily weather conditions in summer than in winter (Kalkstein \& Davis 1989, Langford \& Bentham 1995, Kalkstein \& Greene 1997), although some significant winter relationships have also been found (Glass \& Zack 1979, Larson 1990a,b, Gorjanc et al. 1999). To remove this inherent seasonal cycle from the mortality data, we converted the daily mortality totals into daily mortality anomalies by subtracting from each day's mortality count the median mortality for the month in which the deaths occurred. All subsequent analyses were performed on standardized and de-seasoned daily mortality counts.

Scatterplots of daily mortality versus temperature indicate that death rates increase near the extremes of the temperature distribution at many locations (Bull 1973, Rogot \& Padgett 1976, Bull \& Morton 1978, Wyndham \& Fellingham 1978, Alderson 1985, McKee 1990, Curwen 1991, Kunst et al. 1993, Khaw 1995). That observation led to the development of a 'threshold $\mathrm{AT}^{\prime}$, or the $\mathrm{AT}$ at or beyond which mortality increases above the baseline level (which is zero for the de-seasoned data), for either warm- or cold-season mortality (Kalkstein \& Davis 1989). Our emphasis is on warm-season mortality, so we calculated threshold ATs only at the high end of the AT distribution. Since our null hypothesis is that the mortality-AT time series are stationary, we used the earliest period, or the 1960s-70s 'decade', to identify the threshold AT. We then used tests to determine whether daily mortality totals for days above this constant baseline threshold differed significantly in subsequent decades. For each metropolitan area, histograms of mean mortality $( \pm 2 \mathrm{SE})$ were plotted versus AT. The number and width of class intervals was determined using guidance provided by 3 statistical tests to balance specificity with ease of interpretation (Panofsky \& Brier 1958, Emerson \& Hoaglin 1983). The class interval width was $2^{\circ} \mathrm{C}$ or less for each MSA. In cases when the mean class mortality exceeded zero by more than $2 \mathrm{SE}$ and remained consistently above zero for all higher ATs, the lowest AT with significantly above-normal mortality was defined as the threshold AT. The significance of each threshold was verified by performing a 1-sample, 1-tailed $t$-test for all observations above the threshold AT. The threshold AT analysis was performed separately for each demographic group (total, elderly, white, and non-white) for each MSA.

For example, based upon data from the 1960s-70s, standardized and de-seasoned total mortality in Philadelphia is not elevated over most of the AT range (Fig. 1). However, once ATs exceed $32^{\circ} \mathrm{C}$, mean mortality rates are significantly high (more than $2 \mathrm{SE}$ above zero) and remain above normal for all higher AT class intervals. Thus, we selected a threshold AT of $32^{\circ} \mathrm{C}$ for the total mortality cohort in Philadelphia.

In some cases, there was no threshold AT evident in the 1960s-70s data. In these instances, we then examined the data for thresholds in subsequent decades. If these showed no evidence of a threshold, then no threshold AT was defined for that MSA and demographic group.

To evaluate differences in decadal mean mortality above the threshold AT, 1-way analyses of variance were performed across decades (1960-70s, 1980s, and $1990 \mathrm{~s})$. If the overall ANOVA was significant $(p=0.05)$, 2 -sample $t$-tests were performed between all possible

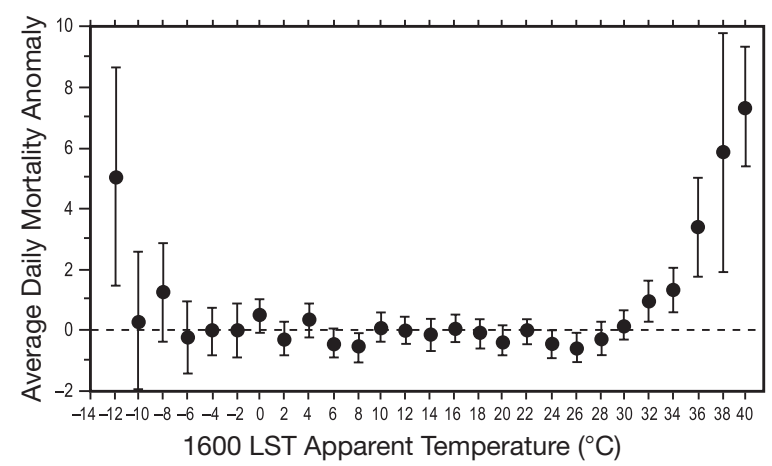

Fig. 1. Total daily mortality anomalies, de-seasoned, for Philadelphia for the years 1964-66 and 1973-79, averaged in $2{ }^{\circ} \mathrm{C}$-wide apparent temperature (AT) class intervals. Error bars represent $\pm 2 \mathrm{SE}$ of the mean. A threshold AT of $32^{\circ} \mathrm{C}$ was chosen because mortality is significantly greater than zero at and above that AT 
decadal pairs. The multiple comparison problem of biasing the Type-I error rate was addressed using guidance from the Scheffe, Bonferroni/Dunn, and Tukey/ Kramer tests (original $\mathrm{p}=0.05$ ) (Milliken \& Johnson 1984).

Overall, our analysis determined (1) whether mortality increases for high ATs; (2) if so, the lowest AT above which mortality increases significantly; (3) whether the interdecadal mortality response has changed; and (4) which decades have significantly higher (or lower) mortality than other decades. Our overarching goal is to analyze the consistency of the relationship between mortality and AT on hot and humid days.

\section{RESULTS AND DISCUSSION}

We use Philadelphia as an example of daily AT-mortality relationships in a northern city. The scatterplot of daily mortality (age-standardized to a city of 1 million people and lagged $1 \mathrm{~d}$ ) versus daily 16:00 $\mathrm{h}$ LST AT has a characteristic U shape, with higher mortality at both low and high ATs (Fig. 2a). This type of U-shaped response over the full temperature spectrum frequently has been observed in locations with weathersensitive populations (Bull 1973, Rogot \& Padgett 1976, Bull \& Morton 1978, Wyndham \& Fellingham 1978, Alderson 1985, Kalkstein \& Davis 1989, McKee 1990, Curwen 1991, Kunst et al. 1993, Khaw 1995). Linear regression analysis indicates that mortality is inversely related to AT $\left(F_{(1,9128)}=1207.4 ; \mathrm{p}<0.0001\right)$. But after seasonal standardization of the mortality data (by subtracting the monthly median mortality from each observation), the relationship becomes positive $\left(F_{(1,9128)}=\right.$ 4.7; $\mathrm{p}<0.0293)$, since winter mortality is now near the mean but summer mortality remains elevated (Fig. 2b). This shift indicates that daily mortality is not strongly linked to daily temperatures at the low end of the AT range in Philadelphia. Elevated mortality counts in winter could be related to higher rates of the transmission of infectious diseases, such as influenza, that are often unrelated to ambient weather conditions. Conversely, at the highest ATs, which mostly occur in summer, there is a marked increase in total mortality and seasonal standardization has little impact (compare Fig. 2a and b), indicating that daily, rather than seasonal, weather dominates the variance at the high AT range. Some warm days, however, show no evidence of elevated deaths. This feature may be 'mortality displacement' - the substantial decline in daily mortality after a high-mortality episode in which many of the more susceptible individuals succumb (Gover 1938, Schuman et al. 1964, Schuman 1972, Marmor 1975, Lyster 1976, Kalkstein 1993, Kunst et al. 1993, Kilbourne 1997). Low death counts on high AT days may
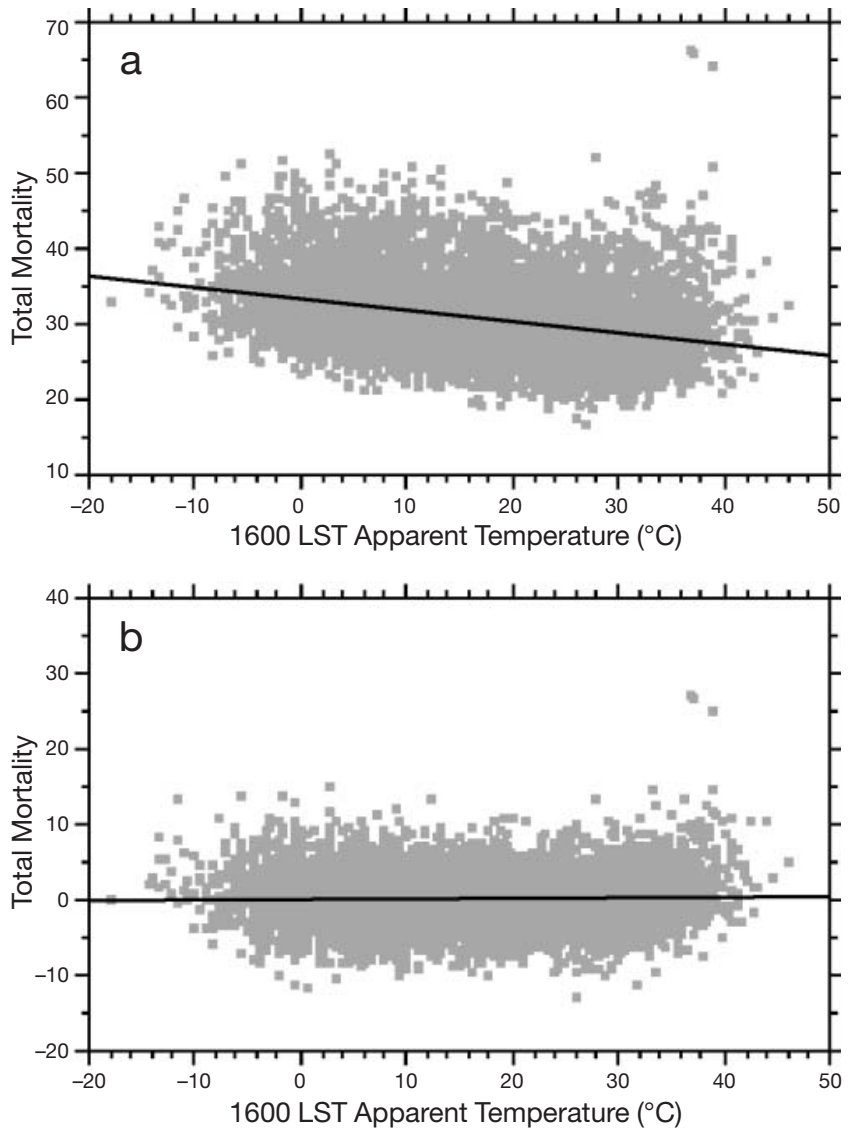

Fig. 2. (a) Scatterplot of daily standardized total mortality for the Philadelphia metropolitan statistical area vs 16:00 h LST AT on the previous day over a 25 yr period from 1964-94. The best fit linear least-squares regression $\left(F_{(1,9128)}=1207.4\right.$; $\mathrm{p}<0.0001)$ demonstrates that mortality rates are higher at low ATs. (b) After adjusting the daily data to remove seasonal differences in mortality rates by subtracting the monthly median mortality from each daily mortality count, there is a weak positive relationship $\left(F_{(1,9128)}=4.7 ; \mathrm{p}<0.0293\right)$. While mortality remains above normal for high ATs, the relationship with low ATs is minimal. This suggests that winter mortality rates are related to the seasonal cycle, while in summer, higher death rates are associated with unusually hot days

also be related to late summer heat events that have a lessened impact because of within-season acclimatization of the populace (Marmor 1975, Greenberg et al. 1983, Kalkstein 1993, WHO/WMO/UNEP 1996).

When Philadelphia's daily total mortality is subdivided by 'decade', several trends become apparent. First, mean mortality rates decline in successive decades over the entire range of ATs (Fig. 3a). Since these data are standardized to account for population changes, this represents a real decline in death rates. Similar responses occurred in all of the cities examined here. Second, the variance in mortality (over a given AT range) likewise declines over time (Fig. 3a,b). Third, and most important, mortality at the highest ATs 

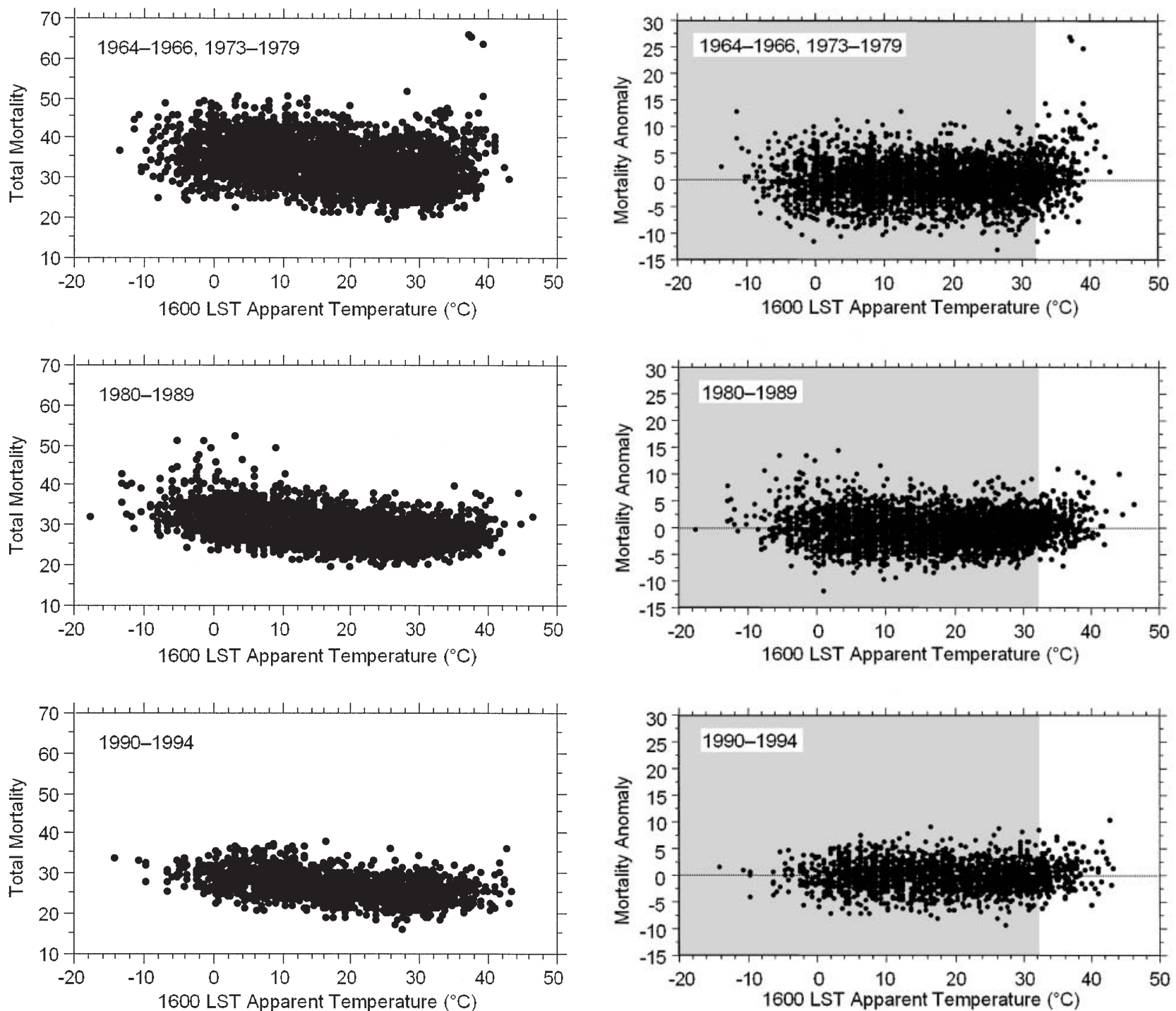

Fig. 3. Left: Scatterplots of Philadelphia daily standardized total mortality vs 16:00 h LST AT on the previous day, organized by 'decade'. Right: Same as at left except the mortality data are de-seasoned (daily anomalies are calculated by subtracting the monthly median mortality from the daily total mortality). The threshold AT is $32^{\circ} \mathrm{C}_{i}$ observations above the threshold AT are in the white region of graphs on right

decreases over time, so that by the 1990s there is little or no relationship between mortality and AT. This weakening of the relationship between daily mortality and AT above the threshold temperature becomes more apparent after standardizing the data to remove seasonal mortality effects (Fig. 3b).

Using data from the 1960s-70s, we identified the AT above which mortality exhibits a statistically significant increase. This 'threshold $\mathrm{AT}^{\prime}$ was calculated for each MSA and demographic group (total, elderly [ $\geq 65 \mathrm{yr}$, white, and non-white). Neither
Charlotte nor Miami showed evidence of a threshold $\mathrm{AT}$, indicating that the populace in these cities is not adversely impacted by high temperature and humidity conditions (Table 1). The 2 northernmost cities,

Table 1. Threshold apparent temperatures $\left(\mathrm{AT},{ }^{\circ} \mathrm{C}\right)$ calculated using data from the 1960s-70s for total mortality and mortality in the elderly, white and non-white subgroups, for each city. -: no threshold AT found

\begin{tabular}{|lcccccc|}
\hline Mortality category & Boston & New York & Philadelphia & Charlotte & Atlanta & Miami \\
\hline Total & 31 & 31 & 32 & - & 37.25 & - \\
Elderly $(\geq 65$ yr old $)$ & 31 & 30 & 33 & - & 38 & - \\
Non-white & - & 32 & 34 & - & 36.5 & - \\
White & 31 & 30 & 32 & - & - & - \\
\hline
\end{tabular}



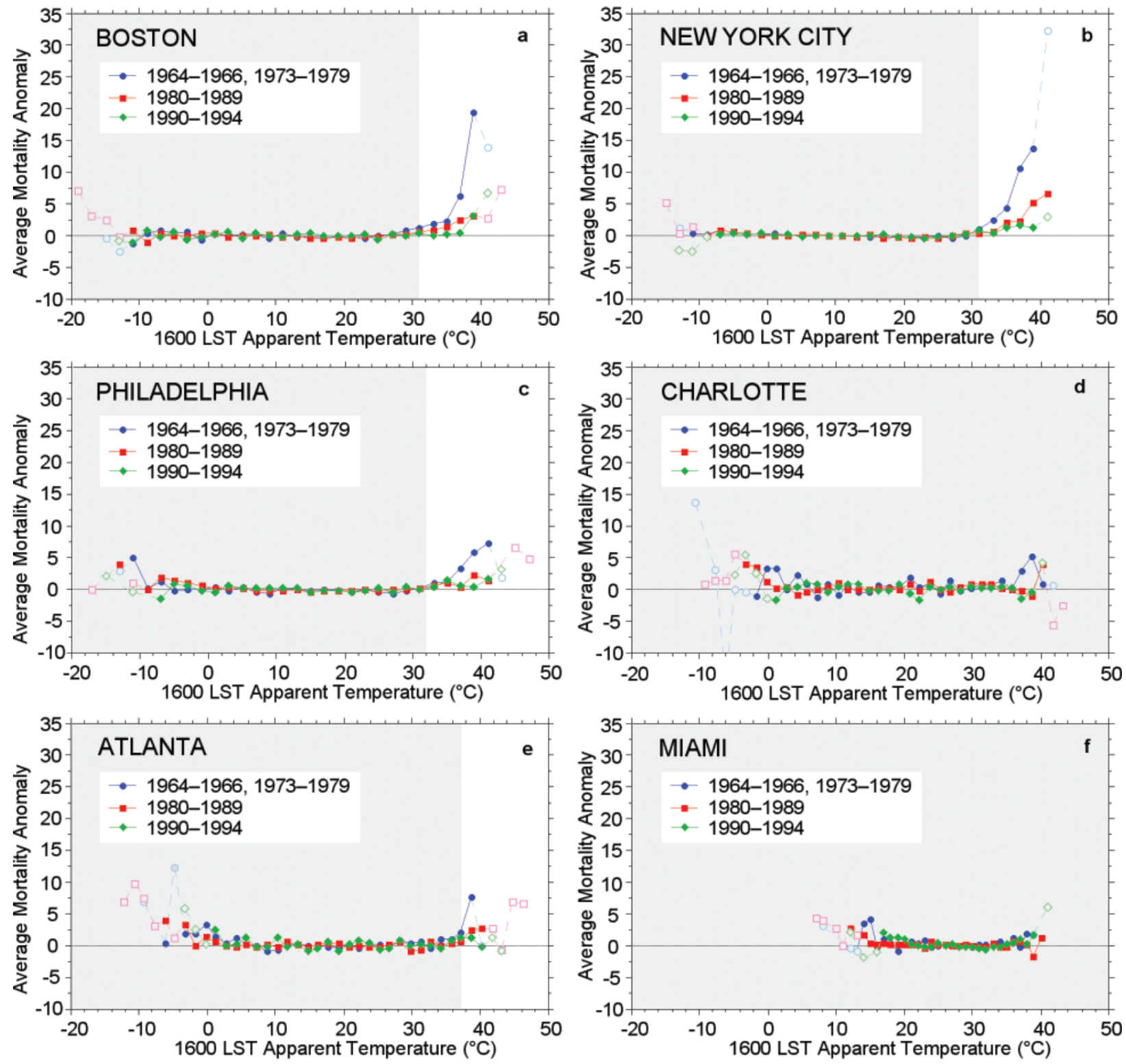

Fig. 4. Mean standardized and de-seasoned total mortality, by 'decade', per AT class interval for (a) Boston, (b) New York City, (c) Philadelphia, (d) Charlotte, (e) Atlanta, and (f) Miami. Values above the threshold AT are plotted in the white region. AT class interval widths are calculated separately for each MSA. Samples with less than 5 observations in a class interval are plotted with open symbols in a lighter shade and connected using dashed lines

Boston and New York, have comparable thresholds, while Philadelphia's threshold ATs are slightly higher. Atlanta has significantly higher threshold ATs than the northern cities, although the white cohort in Atlanta does not exhibit higher death rates on hot, humid days.

To facilitate interpretation, we calculated the mean total mortality anomaly for AT class intervals by decade for each of the 6 MSAs and compared mortality rates above the threshold AT (Fig. 4). For high ATs, there is a marked change in the mortality response over time in Boston, New York, and Philadelphia, the 3 northernmost cities (Fig. 4a-c). In Philadelphia, for example (Fig. 4c), death rates increased for an incremental change in ATs above the $32^{\circ} \mathrm{C}$ AT threshold in the 1960s-70s, but there was little or no change in the 1990s. That decline in the death rate per incremental increase in AT is consistent across cities in the northeastern US, where the populace has historically been susceptible to both prolonged heat waves and shorterterm heat events (Kalkstein \& Valimont 1986, Kalkstein \& Davis 1989). 


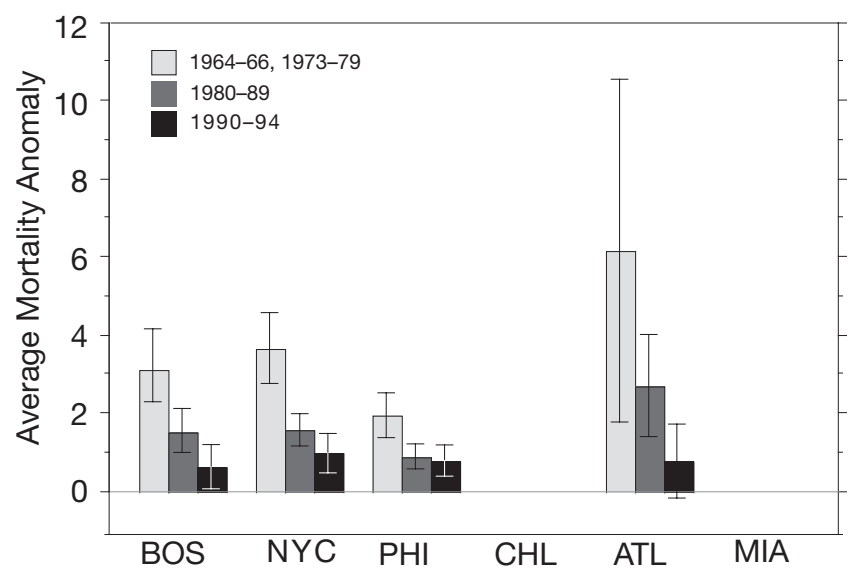

Fig. 5. Mean standardized and de-seasoned total mortality anomalies, by 'decade', for each MSA (BOS: Boston; NYC: New York City; PHI: Philadelphia; CHL: Charlotte; ATL: Atlanta; MIA: Miami). Error bars represent $\pm 2 \mathrm{SE}$

As an example of the decadal decline in total mortality, we computed the average number of extra deaths per day (relative to a standardized population of 1 million people) when afternoon ATs exceeded the threshold in each MSA (Fig. 5). In New York, there were 3.7 excess daily deaths in the 1960s-70s compared with 1.0 excess death in the 1990s. Similar 2-fold to 3-fold multidecadal declines in death rates are evident in Philadelphia and Boston.

In Charlotte and Miami (Fig. $4 \mathrm{~d}, \mathrm{f}$ ), there is no evidence of a threshold AT in any decade. At these and other southern locales, where summer heat and humidity are common, the populace and infrastructure have adapted to the prevalent weather conditions

Table 2. Decadal comparisons of mean standardized mortality above the threshold AT for each MSA by demographic cohort. ${ }^{*}=$ Significant differences in mortality based upon $t$-tests using an equivalent Type-I error rate of 0.05 after accounting for the problem of multiple comparisons. Shaded boxes: no threshold AT. In Philadelphia, for example, there are significant differences in total, white, and elderly mortality between the 1960s-70s and both the 1980s and 1990s. In all statistically significant comparisons, mortality has declined over time

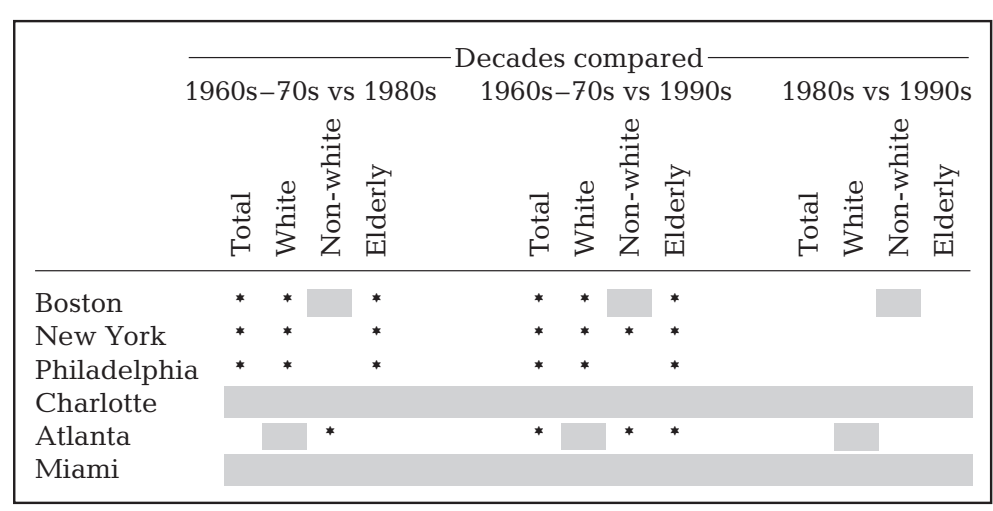

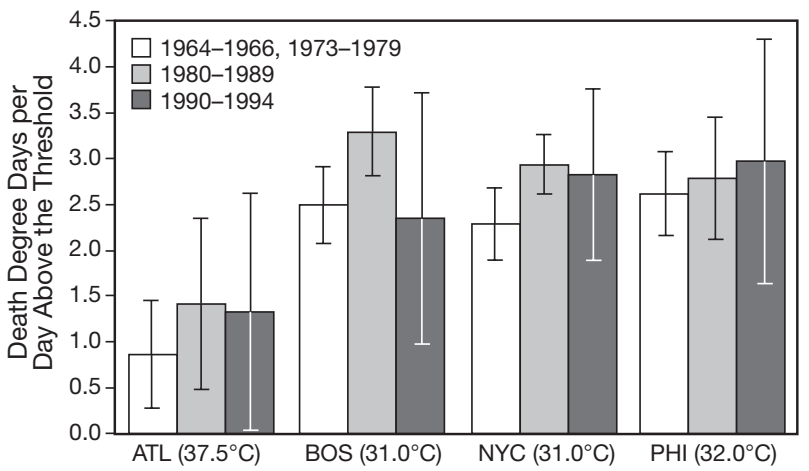

Fig. 6. Mean annual 'death degree days' (accumulated degrees above the threshold AT) per day in which the threshold AT was exceeded, averaged for each 'decade'. Error bars represent $2 \mathrm{SE}$ from the mean. The threshold AT is listed for Atlanta (ATL), Boston (BOS), New York (NYC), and Philadelphia (PHI). Charlotte and Miami are not included because these MSAs have no threshold ATs

(Kalkstein \& Valimont 1986, Kalkstein \& Davis 1989, Davis et al. 1999, 2000). For Atlanta, we did identify a high threshold AT $\left(36.5^{\circ} \mathrm{C}\right)$ near the tail of the AT distribution. Here, the decline in death rates between the 1960s-70s and 1990s is more pronounced than in the other cities and represents a nearly 8-fold decline (Fig. 5). This large relative decline is attributable to the high death rate in the early part of the record-the 1990s death rate for days exceeding the threshold AT in Atlanta is indistinguishable from the mortality rates in the northeastern cities.

Finally, death rates above the threshold AT were compared across decades to determine whether the mean differences are statistically significant. These comparisons were made for all cohortstotal mortality, elderly, white, and nonwhite (Table 2). Since comparisons can only be made in cities with identifiable threshold ATs, these tests were not performed for Charlotte or Miami, which have no thresholds for any demographic group. Furthermore, there is no threshold AT for non-whites in Boston or whites in Atlanta. We speculate that these results could arise from the comparatively small sample sizes of the non-white population in the Boston MSA and the lack of days with very high ATs in Atlanta in the $1960 \mathrm{~s}-70 \mathrm{~s}$, or possibly socioeconomic factors.

In the northern cities, total, white, and elderly death rates were significantly higher in the 1960s-70s than in both the 1980s and 1990s (Table 2). The white and elderly responses are anticipated, since these groups comprise the majority of the 
total mortality pool. There were no significant differences between the 1980s and 1990s, possibly because death rates at high ATs had already declined significantly by the 1980s. For non-whites, mortality at high ATs dropped significantly by the 1990s in New York but not in Philadelphia.

The decadal comparisons in Atlanta are less consistent than in the northern cities (Table 2). Non-white mortality declined significantly in all comparisons, indicating that non-whites in Atlanta have become systematically more immune to the impacts of hot, humid conditions. Non-white mortality fell from an average of 2.1 extra deaths per day in the 1960s-70s to only 0.26 per day in the 1990s. For total and elderly mortality, the decadal comparisons show that Atlanta death rates did not decline as much in the 1980s compared with the northeastern cities, although the smaller sample sizes in Atlanta, because of the high threshold AT, may contribute to the relative robustness of this result.

The emphasis of this analysis is on mortality, the response variable. However, it is worthwhile examining the weather data to determine whether the population in these cities has been exposed to higher ATs over the period of record. To do this, we developed death degree days (DDDs) - the cumulative degrees by which the 16:00 h AT exceeded the threshold AT for each year. The annual DDD total was then divided by the number of days in which the threshold AT was equalled or exceeded to produce a mean daily DDD value for each year. These data were then averaged by 'decade' for each of the 4 MSAs for which we found threshold ATs. Our results demonstrate that while there is a tendency toward more DDDs per day above the threshold AT in later 'decades', these differences are not statistically significant (Fig. 6). In all cases, DDD variations are within $2 \mathrm{SE}$ of the mean. Therefore, mortality rates in the 4 cities are declining over time despite observations of relatively consistent afternoon ATs.

\section{CONCLUSIONS}

In 4 of the 6 cities examined, mortality rates were less influenced by hot and humid summertime conditions in the 1980s and 1990s than they were in the 1960s-70s. These results also hold for an overall ANOVA blocked on decade in which data from all cities are incorporated into a single analysis $(\mathrm{p}<0.0001$ for total, white, and elderly; $\mathrm{p}<0.009$ for non-whites). This reduction in the weather sensitivity of the population has also been found in other cities in the northeastern and northern interior portions of the US, where extreme summer temperatures coupled with high humidity are relatively uncommon (Davis et al. 1999,
2000). By contrast, in warm and humid southern locales such as Charlotte and Miami, the populace exhibits no elevated mortality on days with high ATs for any decade in our record. The lack of an identifiable summer threshold in typically warm locations is consistent with research on other southern US cities (Kalkstein \& Davis 1989, Davis et al. 1999, 2000).

Reductions in weather-related mortality over time (Tuljapurkar et al. 2000) and regional differences in mortality responses are related to several factors. Medical care and access to medical facilities have improved significantly since the 1960s (Goldman \& Cook 1984, Seretakis et al. 1997). In the past 2 decades, airconditioning has become common in households, automobiles, and public places-even in cooler, northern regions, where it was once considered more of a luxury than a necessity. To date, it has been difficult to accurately quantify air-conditioning's role in reducing mortality, but studies in different cities have estimated declines from 21 to $98 \%$ (Rogot et al. 1992, Kalkstein 1993, Semenza et al. 1996, Kilbourne 1997, Chan et al. 2001). Urban and suburban planners and architects have increasingly factored summer heat load into their designs, including more shaded outdoor areas and ready access to potable water. Public health officials, government agencies, and the media have taken more proactive measures to address potential mortality threats on unusually hot and humid days (Kalkstein et al. 1996, McGeehin \& Mirabelli 2001, Palecki et al. 2001). Furthermore, human biophysical acclimatization to high temperatures could also play a role in reduced mortality, both within-season (Marmor 1975, Greenberg et al. 1983, Kalkstein 1993, WHO/WMO/ UNEP 1996) and over longer periods of time (Bonner et al. 1976, Wyndham et al. 1976, Frost \& Auliciems 1993). In effect, the mortality response in northeastern cities has become more like that of southeastern cities in recent decades.

Differences in mortality responses between nonwhites and other demographic groups could be related to socioeconomic factors, including income, access to air-conditioning, and the availability of quality health care (Marmot 1986, Pappas et al. 1993). Non-white mortality rates are less consistent across MSAs than the other cohorts, but no physiological predisposition to heat vulnerability based on race has been identified (Kilbourne 1997).

In conclusion, based upon this research, concerns about increasing heat-related mortality rates in the eastern US arising from human-induced climate change appear to be unfounded. In all of the cities examined here, mortality rates on hot and humid days are steady or have declined over time, showing strong support for an overall desensitization of the populace to hot and humid conditions in the warm season. 
Similar results have been found for most major metropolitan areas in the continental US (Davis et al. 1999, 2000).

Weather-mortality models developed only using post-1980 data would show little or no elevated mortality on even the most uncomfortable summer days. The inherent non-stationarity of the mortality-apparent temperature time series indicates that most contemporary projections of future US mortality rates are overestimates. Therefore, observed trends in the weather sensitivity of the US population must be carefully considered in the development of climate change impact models.

Acknowledgements. We extend our thanks to L. S. Kalkstein and D. Graybeal (University of Delaware) for providing the raw mortality data used in this study and for their assistance in reading the digital data sets. We also thank W. A. Knaus, M. Mann, T. Chang, D. Wagner and B. Hayden (University of Virginia) and M. McGeehin and D. Gubler (Centers for Disease Control) for their assistance with this research and comments on an earlier manuscript draft. Finally, we appreciate the feedback provided by 3 anonymous reviewers, particularly the extensive comments of one referee who very carefully edited our original manuscript and provided a series of excellent suggestions for revisions.

\section{LITERATURE CITED}

Alderson MR (1985) Season and mortality. Health Trends $17: 87-96$

Anderson RN, Rosenberg HM (1998) Age standardization of death rates: implementation of the year 2000 standard. National Vital Statistics Reports 47(3). National Center for Health Statistics, Hyattsville, MD

Applegate WB, Runyan JW Jr, Brasfield L, Williams MLM, Konigsberg C, Fouche C (1981) Analysis of the 1980 heat wave in Memphis. J Am Geriatr Soc 29:337-342

Ayoade JO (1978) Spatial and seasonal patterns of physiologic comfort in Nigeria. Arch Meteorol Geophys Biokl Ser B 26:319-337

Bonner RM, Harrison MH, Hall CJ, Edwards RJ (1976) Effect of heat acclimatization in intravascular responses to acute heat stress in man. J Appl Physiol 41:708-713

Bridger CA, Ellis FP, Taylor HL (1976) Mortality in St. Louis, Missouri, during heat waves in 1936, 1953, 1954, 1955 and 1966. Environ Res 12:38-48

Bull GM (1973) Meteorological correlates with myocardial and cerebral infarction and respiratory disease. Br J Prev Soc Med 27:108-113

Bull GM, Morton J (1978) Environment, temperature and death rates. Age Aging 7:210-224

Chan NY, Stacey MT, Smith AE, Ebi KL, Wilson TF (2001) An empirical mechanistic framework for heat-related illness. Clim Res 16:133-143

Chestnut LG, Breffle WS, Smith JB, Kalkstein LS (1998) Analysis of differences in hot-weather-related mortality across 44 U.S. metropolitan areas. Environ Sci Policy $1: 59-70$

Curwen M (1991) Excess winter mortality: a British phenomenon? Health Trends 1990 22:169-175

Davis RE, Knappenberger PC, Novicoff WM, Michaels PJ, Balling RC Jr (1999) Decadal changes in weather/human mortality relationships in U.S. cities. In: de Dear RJ, Potter J (eds) Proc 15th Int Cong Biometeorol, Macquarie University, Sydney

Davis RE, Knappenberger PC, Novicoff WM, Michaels PJ (2000) Decadal changes in summer mortality in the United States. In: Proc 12th Conf Appl Climatol, Am Meteorol Soc, Boston, p 184-187

Donaldson GC, Keatinge WR (1997) Early increases in ischaemic heart disease mortality dissociated from and later changes associated with respiratory mortality after cold weather in south east England. J Epidemiol Comm Health 51:643-648

Emerson JD, Hoaglin DC (1983) Stem and leaf displays. In: Hoaglin DC, Mosteller F, Tukey JW (eds) Understanding robust and exploratory data analysis. Wiley, New York, p 7-32

Eurowinter Group (1997) Cold exposure and winter mortality from ischaemic heart disease, cerebrovascular disease, respiratory disease, and all causes in warm and cold regions of Europe. Lancet 349:1341-1346

Frost DB, Auliciems A (1993) Myocardial infarct death, the population at risk, and temperature habituation. Int J Biometeorol 37:46-51

Gaffen DJ, Ross RJ (1998) Increased summertime heat stress in the U.S. Nature 396:529-530

Glass R, Zack M (1979) Increase in deaths from ischemic heart disease after blizzards. Lancet 3:485-487

Goldman L, Cook EF (1984) The decline in ischaemic heart disease mortality rates: an analysis of the comparative effects of medical interventions and changes in lifestyle. Ann Intern Med 101:825-836

Gorjanc ML, Flanders WD, VanDerslice J, Hersh J, Malilay J (1999) Effects of temperature and snowfall on mortality in Pennsylvania. Am J Epidemiol 149:1152-1160

Gover M (1938) Mortality during periods of excessive temperature. Public Health Rep 53:1122-1143

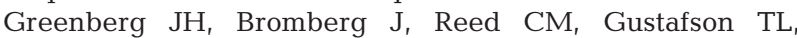
Beauchamp RA (1983) The epidemiology of heat-related deaths, Texas-1950, 1970-79 and 1980. Am J Public Health 30:130-136

Henschel A, Burton LL, Margolies L, Smith JE (1969) An analysis of the heat deaths in St. Louis during July 1966. Am J Public Health 59:2232-2242

Höppe P (1999) The physiological equivalent temperature-a universal index for the biometeorological assessment of the thermal environment. Int J Biometeorol 43:71-75

Jones TS, Liang AP, Kilbourne EM, Griffin MR, Patriarca PA, Wassilak SG, Mullan RJ, Herrick RF, Donnell HD Jr, Choi K, Thacker SB (1982) Morbidity and mortality associated with the July 1980 heat wave in St. Louis and Kansas City, Missouri. J Am Med Assoc 247:3327-3331

Kalkstein LS (1993) Health and climate change-direct impacts in cities. Lancet 342:1397-1399

Kalkstein LS, Davis RE (1989) Weather and human mortality: an evaluation of demographic and interregional responses in the United States. Ann Assoc Am Geogr 79:44-64

Kalkstein LS, Greene JS (1997) An evaluation of climate/ mortality relationships in large U.S. cities and the possible impacts of a climate change. Environ Health Perspec 105:84-93

Kalkstein LS, Valimont KM (1986) An evaluation of summer discomfort in the United States using a relative climatological index. Bull Am Meteorol Soc 67:842-848

Kalkstein LS, Jamason PF, Greene JS, Libby J, Robinson L (1996) The Philadelphia hot weather-health watch/warning system: development and application, summer 1995. Bull Am Meteorol Soc 77:1519-1528 
Katsouyanni K, Pantazopoulou A, Touloumi G, Tselepidaki I, Moustris K, Asimakopoulos D, Poulopoulou G, Trichopoulos D (1993) Evidence for interaction between air pollution and high temperature in the causation of excess mortality. Arch Environ Health 48:235-242

Keatinge WR, Coleshaw SRK, Easton JC (1986) Increased platelet and red cell counts, blood viscosity and plasma cholesterol levels during heat stress, and mortality from coronary and cerebral thrombosis. Am J Med 81:795-800

Khaw KT (1995) Temperature and cardiovascular mortality. Lancet 345:337-338

Kilbourne EM (1997) Heat waves and hot environments. In: Noji EK (ed) The public health consequences of disaster. Oxford University Press, New York, p 245-269

Kunst AE, Looman CWN, Mackenbach JP (1993) Outdoor air temperature and mortality in the Netherlands: a time series analysis. Am J Epidemiol 137:331-341

Langford IH, Bentham G (1995) The potential effects of climate change on winter mortality in England and Wales. Int J Biometeorol 38:141-147

Landsberg HE (1981) The urban climate. Academic Press, New York

Larsen U (1990a) Short-term fluctuations in death by cause, temperature, and income in the United States 1930-1985. Soc Biol 37:172-187

Larsen U (1990b) The effects of monthly temperature fluctuations on mortality in the United States from 1921 to 1985. Int J Biometeorol 34:136-145

Lee DHK (1980) Seventy-five years of searching for a heat index. Environ Res 22:331-356

Lerchl A (1998) Changes in the seasonality of mortality in Germany from 1946 to 1995: the role of temperature. Int J Biometeorol 42:84-88

Lye M, Kamal A (1977) The effects of a heat wave on mortality rates in elderly patients. Lancet 1:529-531

Lyster WR (1976) Death in summer [letter]. Lancet 2:469

Mandell GL, Bennett JE, Dolin R (1995) Mandell, Douglas and Bennett's principles and practice of infectious diseases, 4th edn. Churchill Livingstone, New York

Marmor M (1975) Heat wave mortality in New York City, 1949 to 1970. Arch Environ Health 30:130-136

Marmot MG (1986) Mortality decline and widening social inequalities. Lancet 2:274-276

Matzarakis A, Mayer H, Iziomon MG (1999) Applications of a universal thermal index: physiological equivalent temperature. Int J Biometeorol 43:76-84

McGeehin MA, Mirabelli M (2001) The potential impacts of climate variability and change on temperature-realted morbidity and mortality in the United States. Environ Health Perspec 109:185-198

McKee CM (1990) Deaths in winter in Northern Ireland: the role of low temperature. Ulster Med J 59:17-22

Milliken GA, Johnson DE (1984) Analysis of messy data, Vol I: designed experiments. Lifetime Learning Publications, Belmont, CA

Monto AS, Kioumehr F (1975) The Tecumseh study of respiratory illness. IX. Occurrence of influenza in the community, 1966-1971. Am J Epidemiol 102:553-563

National Center for Health Statistics (1994) Compressed mortality file, 1964-1994. US Dept Health Human Serv, Public Health Serv, CDC. Atlanta, GA

Editorial responsibility: Andrew Comrie,

Tucson, Arizona, USA
National Climatic Data Center (1993) Solar and meteorological surface observation network 1961-1990. National Climatic Data Center, Asheville, NC

National Climatic Data Center (1997) Hourly United States weather observations 1990-1995. National Climatic Data Center, Asheville, NC

Oechsli FW, Buechli RW (1970) Excess mortality associated with three Los Angeles September hot spells. Environ Res 3:277-284.

Palecki MA, Changnon SA, Kunkel KE (2001) The nature and impacts of the July 1999 heat wave in the midwestern United States: learning from the lessons of 1995. Bull Am Meteorol Soc 82:1353-1367

Panofsky HA, Brier GW (1958) Some applications of statistics in meteorology. The Pennsylvania State University Press, University Park

Pappas G, Queen S, Hadden W, Fisher G (1993) The increasing disparity in mortality between socioeconomic groups in the United States, 1960 and 1986. N Engl J Med 329: 103-109

Rogot E, Padgett SJ (1976) Associations of coronary and stroke mortality with temperature and snowfall in selected areas of the United States, 1962-1966. Am J Epidemiol 103:565-575

Rogot E, Sorlie PD, Backlund E (1992) Air-conditioning and mortality in hot weather. Am J Epidemiol 136:106-116

Schuman SH (1972) Patterns of urban heat-wave deaths and implications for prevention: data from New York and St. Louis during July, 1966. Environ Res 5:59-75

Schuman SH, Anderson CP, Oliver JT (1964) Epidemiology of successive heat waves in Michigan in 1962 and 1963. J Am Med Assoc 180:131-136

Semenza JC, Rubin CH, Falter KH, Selanikio JD, Flanders WD, Howe HL, Wilhelm JL (1996) Heat-related deaths during the July 1995 heat wave in Chicago. N Engl J Med 335:84-90

Seretakis D, Lagiou P, Lipworth L, Signorello LB, Rothman KJ, Trichopoulos D (1997) Changing seasonality of mortality from cornonary heart disease. J Am Med Assoc 278: 1012-1014

Smoyer KE, Rainham GC, Hewko JN (2000) Heat-stressrelated mortality in five cities in Southern Ontario: 1980-1996. Int J Biometeorol 44:190-197

Steadman RG (1979) The assessment of sultriness. Part I: a temperature-humidity index based on human physiology and clothing science. J Appl Meteorol 18:861-873

Steadman RG (1984) A universal scale of apparent temperature. J Clim Appl Meteorol 23:1674-1687

Tuljapurkar S, Li N, Boe C (2000) A universal pattern of mortality decline in the G7 countries. Nature 405:789-792

United States Dept of Commerce (1992) 1992, 1982 and 1973. General population characteristics, United States. US Dept of Commerce, Bureau of the Census, Washington, DC

WHO/WMO/UNEP (1996) Climate and health: the potential impacts of climate change. WHO/WMO/UNEP, Geneva

Wyndham CH, Fellingham SA (1978) Climate and disease. S Afr Med J 53:1051-1061

Wyndham CH, Rogers GG, Senay LC, Mitchell D (1976) Acclimatization in a hot humid environment: cardiovascular adjustments. J Appl Physiol 40:779-785

Submitted: September 11, 2001; Accepted: December 14, 2001 Proofs received from author(s): July 11, 2002 